\title{
Efeito da condensação e queima na formação de defeitos microestruturais em cerâmicas feldspáticas dentárias
}

\section{(Effect of compaction method and multiple firing on the formation of microstructural defects in feldspar-based dental ceramics)}

\author{
J. C. M. de Souza, R. M. do Nascimento, A. E. Martinelli \\ Departamento de Engenharia de Materiais, Universidade Federal do Rio Grande do Norte, \\ Campus Lagoa Nova, Natal, RN 59072-970 \\ juliocmat@yahoo.com.br,rmaribondo@ufrnet.br,aemart@uol.com.br
}

\begin{abstract}
Resumo
As cerâmicas feldspáticas dentárias são rotineiramente empregadas para reconstruções protéticas dentárias unitárias ou extensas, associadas a uma subestrutura metálica. Tendo em vista a sensibilidade técnica na confecção deste tipo restauração dentária, o objetivo deste estudo foi analisar a influência de múltiplas queimas e técnicas de condensação na presença de defeitos na microestrutura de cerâmicas feldspáticas dentárias. Os pós de duas diferentes marcas comerciais de cerâmicas feldspáticas convencionais dentina (A e B) foram caracterizados por difração de raios $\mathrm{X}(\mathrm{DRX})$ e, em seguida, por granulometria com um granulômetro associado a um programa analisador de tamanho de partículas. Para a caracterização da microestrutura foram confeccionadas amostras das cerâmicas A e B por meio de três técnicas: 1condensada sem vibração ultrasônica e queima única; 2- condensada sob vibração ultrasônica e queima única; 3- condensada sob vibração ultrasônica e quatro queimas. As amostras foram lixadas e polidas, caracterizadas microestruturalmente por microscopia eletrônica de varredura (MEV-EDS) e microscopia ótica, e compararadas a uma cerâmica feldspática dentária termoprensável (C). A análise por DRX mostra a leucita como a única fase cristalina. A distribuição do tamanho de partículas das cerâmicas A e B apresentou aspecto trimodal, com presença de partículas um pouco maiores para a cerâmica B. A análise microestrutural da superfície revelou a presença de poros em todas as cerâmicas. No entanto, a quantidade de poros foi maior nas amostras que foram confeccionadas sem vibração e absorção de água e sinterizadas por queima única. As amostras que foram submetidas a quatro queimas apresentaram um menor volume de poros, porém com o aparecimento de trincas geradas durante o resfriamento. A técnica manual de condensação adequada sob vibração ultrasônica e posterior tratamento térmico em forno proporcionou uma quantidade de poros semelhantes à cerâmica termoprensável.
\end{abstract}

Palavras-chave: cerâmica dentária, porosidade, trincas.

Abstract

Feldspar-based dental ceramics joined to metallic substructures are frequently used for unitary or extensive dental prosthetic restorations. As the manufacturing technique significantly affects the performance of dental ceramic restorations, the aim of this study was to evaluate the effect of multiple firing cycles and compaction method on the formation of microstructural defects in feldspar-based dental ceramics. Commercial powders of two dentin feldspar-based ceramics (A and B) were characterized by XRD and particle size distributions. After that, ceramic samples were produced by compaction without ultrasonic vibration and fired once, compaction with ultrasonic vibration and fired once, and finally, compaction with ultrasonic vibration and fired four times. The fired materials were ground and polished, characterized by SEM-EDS and optical microscopy. A hot-pressed feldspar-based ceramic (C) was used for comparison purpose. The XRD analysis showed the presence of leucite as the only crystalline phase. The particle size distributions of both ceramics tested were trimodal with the presence of larger particles in B ceramic. The microstructural analysis revealed the presence of pores in the fired ceramics. The volume of pores was larger in the compacted samples without ultrasonic vibration. The samples submitted to four firing cycles had a smaller number of pores, however, with the presence of cracks generated during cooling because of differences in thermal expansion coefficients. Therefore, the results showed that the adequate compaction and firing procedure involved ultrasonic vibration followed by firing once, which provides microstructural characteristics similar to hot-pressed ceramics.

Keywords: dental ceramics, porosity, cracks.

\section{INTRODUÇÃO}

As cerâmicas dentárias à base de feldspatos são rotineiramente empregadas para reconstruções protéticas dentárias unitárias ou extensas, associadas a uma subestrutura metálica. Outra indicação destes materiais está na confecção de facetas estéticas para recobrimento de dentes bastante escurecidos que não respondem ao tratamento clareador dentário. A principal vantagem deste material é a de simular, o mais fielmente possível, a cor natural dos dentes tornando-se esteticamente o material de escolha para reconstruções dentárias complexas. Na Fig. 1 é apresentado 
esquematicamente a subestrutura metálica e as diversas camadas de porcelana utilizada em uma prótese dentária em relação aos tecidos orais mais próximos (dentina e margem da gengiva).

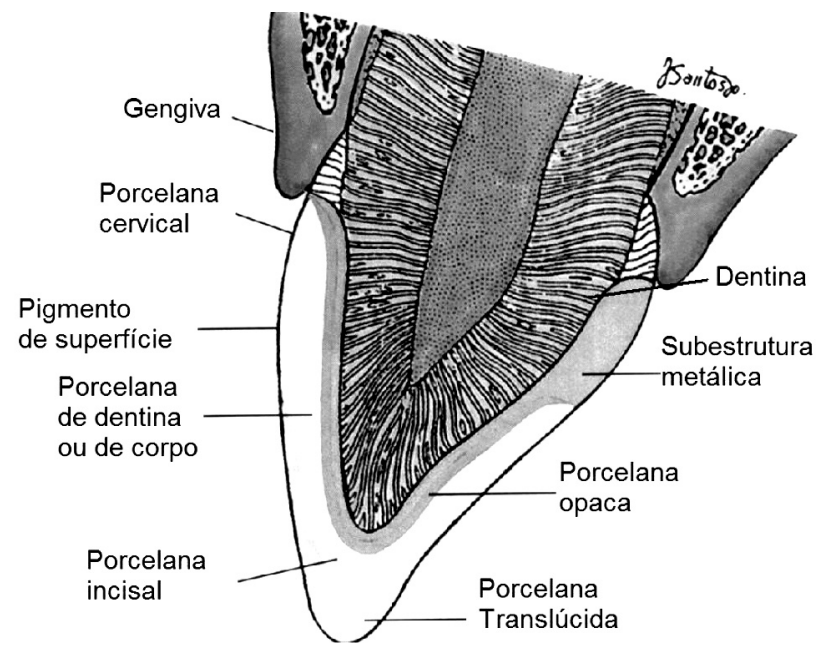

Figura 1: Desenho esquemático da secção transversal de uma prótese unitária metal-cerâmica [1].

[Figure 1: Schematic illustration of the traverse cut of a metalceramic unitary prosthesis.]

A cerâmica opaca, primeira camada a ser aplicada, contém óxidos opacificantes e corantes responsáveis pela diminuição da passagem de luz através desta camada e assim diminuindo a percepção da cor escura da subestrutura metálica e transmitindo a cor da estrutura de dentina interna de um dente natural [1]. Posteriormente à queima da camada de opaco, a camada de dentina é aplicada. Esta cerâmica é mais translúcida e possui óxidos corantes para simular cores de dentina desejadas dependendo da cor dos dentes naturais vizinhos. Mais externamente, a camada de esmalte e incisal são aplicadas simulando as camadas de um dente natural. Finalmente, após a queima de todas as camadas, uma cerâmica mais fluida, chamada glaze, é aplicada sobre a superfície com objetivo de recobrir defeitos melhorando, assim, as propriedades mecânicas e ópticas da restauração cerâmica.

Para a confecção das próteses metalocerâmicas, a cerâmica feldspática é submetida a várias queimas até a conformação da geometria final da restauração protética.

Tabela I - Cerâmicas dentárias.

[Table I - Dental ceramics.]

\begin{tabular}{ccccc}
\hline Grupos & Classificação & 1Queima & $\begin{array}{c}\text { Vibração + } \\
\text { 1 Queima }\end{array}$ & $\begin{array}{c}\text { Vibração }+ \\
\text { 4 Queimas }\end{array}$ \\
\hline A & Convencional & A1 & A2 & A3 \\
B & Convencional & B1 & B2 & B3 \\
C & Termoprensável & C & & \\
\hline
\end{tabular}

Alguns estudos reportam a dificuldade técnica na aplicação das camadas de cerâmica sobre a subestrutura metálica no que diz respeito a sua sensibilidade a erros por parte do técnico em prótese dentária $[2,3]$. A cerâmica dentária convencional é apresentada como um pó fino o qual é misturado com água e condensado para formar uma pasta que pode ser conformada na geometria desejada sobre a subestrutura metálica. A técnica de condensação da pasta é manual variando entre a técnica de vibração ultrasônica e vibração com auxílio do lecron (instrumento metálico) e entre os laboratórios de prótese dentária. Nem sempre o teor de água pode ser controlado em todas as camadas havendo camadas com uma condensação satisfatória e camadas com espaços de ar entre as partículas ou uma grande distância entre as partículas. Em particular, poros são frequentemente encontrados na microestrutura da cerâmica feldspática e podem estar associados à variação do volume de água adicionado à cerâmica em pó. $\mathrm{O}$ aumento do volume de água reduz o teor relativo de sólidos e compromete o empacotamento das partículas, e a liberação de vapor durante a sinterização [4].

$\mathrm{Na}$ composição das cerâmicas feldspáticas, há aproximadamente $78-94 \%$ de feldspatos de sódio e/ou potássio e $6-22 \%$ de leucita, dependendo da marca comercial [5-7]. O conteúdo de leucita presente tem o papel primordial de aumentar o coeficiente de expansão térmica da cerâmica e também melhorar as propriedades mecânicas do material, conforme reportado por vários autores $[2,5,8]$. Há estudos que reportam o aumento da tenacidade $\left(K_{I C}\right)$ à fratura do material cerâmico à medida que se aumenta o conteúdo de leucita [5]. No entanto, a diferença de expansão térmica entre as fases vítrea e de leucita podem originar as trincas microestruturais após queimas repetidas [8-10].

As diversas queimas podem promover o aparecimento de trincas as quais podem ser detectadas em todas as camadas aplicadas $[1,11]$. Poros e trincas são locais de concentrações de tensões e de substâncias ácidas presentes no meio oral [9]. Além do mais, a excessiva porosidade pode deixar a superfície mais opaca. As trincas são originárias da diferença do coeficiente de expansão térmica entre as fases constituintes quando submetidas a diversas queimas e rápidos ciclos de queima [8-10]. As trincas podem ainda se propagar sob condições de solicitações mecânicas sendo mais rápido, este crescimento catastrófico, em ambiente ácido [12] ou em um meio simplesmente aquoso [13, 14].

O objetivo deste estudo é analisar a influência de múltiplas queimas e técnicas de condensação na presença de defeitos na microestrutura de cerâmicas feldspáticas dentárias.

\section{MATERIAIS E MÉTODOS}

Para as análises foram utilizadas três diferentes marcas comerciais de cerâmicas dentárias de dentina, sendo duas feldspáticas convencionais $(\mathrm{AeB})$ e uma cerâmica feldspática injetável sob termopressão (C). Inicialmente foi realizada a análise por DRX para se identificar as fases constituintes. As amostras cerâmicas foram analisadas por DRX pelo método 
do pó em um difratômetro Shimadzu 6000 . A radiação foi $\mathrm{Cu}$ $\mathrm{K}_{\alpha}(1,54056 \AA)$, voltagem de $40 \mathrm{kV}$ e corrente de $30 \mathrm{~mA}$. A faixa de varredura foi de $5^{\circ}$ a $75^{\circ}$ sob velocidade de $1,5^{\circ} \mathrm{min}^{-1}$, passo de $0,02^{\circ}$ e tempo por passo de $1 \mathrm{~s}$.

Em seguida, a distribuição do tamanho das partículas dos pós foi caracterizada por meio de granulometria a laser com um analisador de partículas CILAS modelo 920L. O meio dispersante consistiu de detergente e o tempo de ultra-som foi de $90 \mathrm{~s}$.

As amostras cerâmicas foram confeccionadas em um laboratório de prótese dentária seguindo as recomendações dos fabricantes e divididas em 3 grupos de cerâmicas (A, $\mathrm{B}$ e C). Para a confecção das amostras, o pó cerâmico foi misturado com água destilada em uma geometria em forma de discos com dimensões de $5 \mathrm{~mm}$ de diâmetro e $2 \mathrm{~mm}$ de espessura. Para cada cerâmica convencional (A e B) foram preparadas três amostras: 1- condensada sem vibração ultrasônica e queima única; 2- condensada sob vibração ultrasônica e queima única; 3- condensada sob vibração ultrasônica e quatro queimas, Tabela I.

A cerâmica $C$ foi a única que não passou por condensação manual e não foi sinterizada sob quatro queimas devido ao procedimento de queima ser realizado sob termopressão. A cerâmica termoprensável é disponibilizada pelo fabricante em discos sinterizados os quais são aquecidos em forno de sinterização, com um ciclo de queima determinado pelo fabricante, e então injetada em um molde sob pressão. Enquanto as demais cerâmicas são sinterizadas a partir da mistura do pó e água e aquecimento em forno com um ciclo de queima determinado pelo fabricante.

Para a análise da microestrutura, as amostras foram submetidas às etapas de embutimento em resina, lixamento $\mathrm{e}$ polimento para análise por microscopia ótica e eletrônica. $\mathrm{O}$ lixamento foi realizado em uma lixadeira mecânica rotativa com lixas de carbeto de silício nas seguintes granulações: $320,400,600$ e 1200 mesh (grãos/pol ${ }^{2}$ ). A etapa de polimento foi realizada manualmente com a utilização de pasta de diamante, nas granulometrias: 6,3 e $1 \mu \mathrm{m}$.

A microestrutura das cerâmicas foi caracterizada por meio de um microscópio ótico Shimadzu SSX-550, associado a um programa de computador para quantificar o número de defeitos. A caracterização em microscópio eletrônico de varredura associado ao EDS foi necessária para avaliar a relação entre a origem dos defeitos e fases presentes na microestrutura.

\section{RESULTADOS E DISCUSSÃO}

Este estudo avaliou a sensibilidade técnica, no que diz respeito à condensação e tratamento térmico do material, sobre o aparecimento de defeitos na superfície de cerâmicas dentárias. Para isto foi necessário análises químicas e físicas do material em pó para o conhecimento das fases químicas presentes e distribuição de tamanho de partículas do pó.

A Fig. 2 apresenta o difratograma obtido por DRX do pó da cerâmica A. O difratograma apresenta picos mais facilmente detectáveis de leucita, em $26,5^{\circ}$, e uma grande quantidade de fase vítrea.

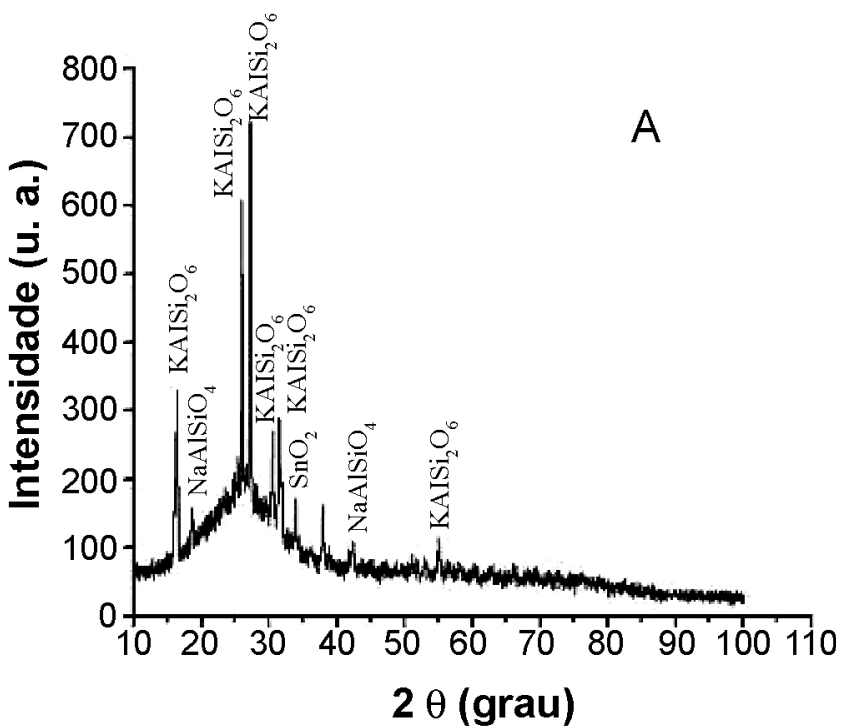

Figura 2: Difratograma da cerâmica dentária A. [Figure 2: X-ray diffraction pattern of the $A$ dental ceramic.]

O difratograma da cerâmica B apresentou-se semelhante ao difratograma da cerâmica A, como pode ser visto na Fig. 3.

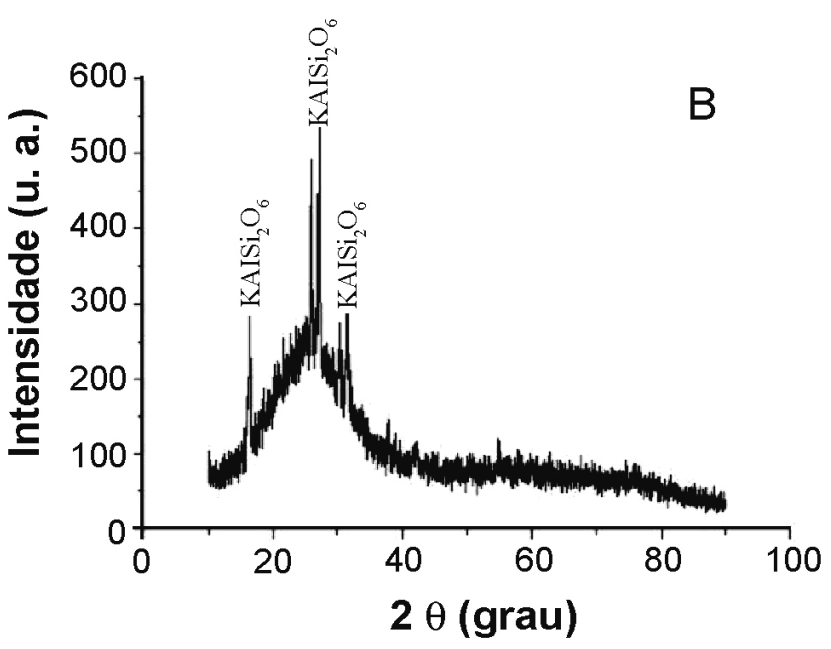

Figura 3: Difratograma da cerâmica dentária B.

[Figure 3: X-ray diffraction pattern of B dental ceramic.]

As cerâmicas de dentina, denominadas também cerâmicas de corpo, têm a função de proporcionar maior translucidez para simular a estrutura de dentina dos dentes naturais. Isso explica a grande presença de fase vítrea nos difratogramas. A única fase cristalina, a leucita, é incorporada para elevar o coeficiente de expansão térmica para um valor próximo aos das ligas metálicas para subestruturas de sistemas metalcerâmicos dentários. Observa-se ainda que a intensidade dos picos de leucita para a cerâmica A é maior comparado à cerâmica $\mathrm{B}$ podendo indicar o maior teor de leucita na cerâmica A.

Alguns pesquisadores analisaram quantitativamente $\mathrm{o}$ 
conteúdo de leucita a partir das áreas dos principais picos obtidos por DRX $[6,7,15,16]$. Pesquisadores na área encontraram uma concentração de $22,6 \%$ de leucita para a Ceramco II e $8,1 \%$ para a Finesse [6]. O aumento do teor de leucita proporciona um aumento da tenacidade à fratura e da resistência mecânica à flexão. Além, do mais aumenta o coeficiente de expansão térmica para que o material seja unido a ligas metálicas constituindo assim um sistema metalcerâmica.

A Fig. 4 revela a distribuição de tamanho das partículas para as amostras cerâmicas A e B.

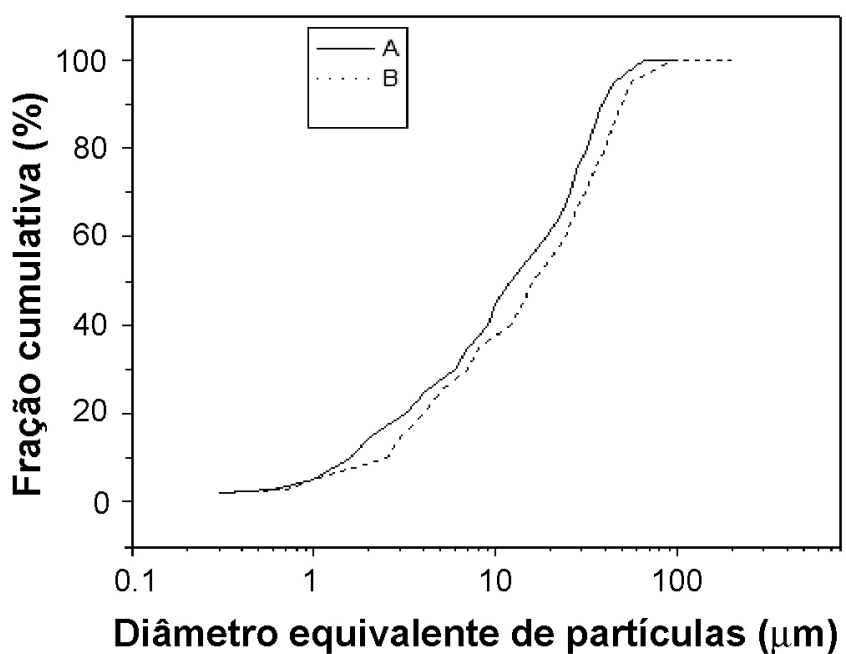

Figura 4. Distribuição granulométrica do pó cerâmico A e B.

[Figure 4: Particle size distributions of the $A$ and $B$ dental ceramic powders.]

AFig. 4 mostra que a totalidade das partículas da cerâmica A apresenta diâmetro inferior a $65 \mu \mathrm{m}$ e $50 \%$ destas partículas diâmetro inferior a $12 \mu \mathrm{m}$. O diâmetro médio das partículas da cerâmica A encontra-se por volta de $17 \mu \mathrm{m}$. Já a cerâmica B apresenta partículas com diâmetro um pouco maior. Há partículas com até $100 \mu \mathrm{m}$, entretanto $50 \%$ das partículas apresentam diâmetro inferior a $16 \mu \mathrm{m}$. O diâmetro médio das partículas da cerâmica B é de $22 \mu \mathrm{m}$. Entretanto, pode haver uma pequena discrepância na distribuição de tamanhos de partículas entre os lotes comerciais das cerâmicas devido a uma moagem deficiente ou contaminação no armazenamento causando uma aglomeração das partículas. Um estudo relacionado ao empacotamento de misturas com distribuição de partículas esféricas de um só tamanho, distribuição com dois e três tamanhos diferentes de partículas, monomodal, bimodal e trimodal, respectivamente, revela $40 \%$ de espaços vazios para o material de partículas de um só tamanho, $18,5 \%$ para o material bimodal e $15,5 \%$ para o trimodal [17]. Outro estudo sobre o empacotamento de partículas esféricas revela resultados similares [18]. No caso de misturas bimodais e trimodais, partículas pequenas tendem a fundir nos interstícios do agregado de partículas maiores melhorando o empacotamento e, consequentemente, aumentando a densidade do material e diminuindo a contração de sinterização [19]. Analisando os resultados da granulometria, observa-se que a cerâmica A apresentou uma distribuição de partículas trimodal ideal para promover um ótimo empacotamento das partículas, aumentando a densidade do material e minimizando a presença de poros após a queima. Já, a cerâmica $\mathrm{B}$ apresentou distribuição discretamente trimodal.

A análise microestrutural da superfície revelou a presença de poros em todas as cerâmicas. No entanto, a quantidade de poros foi maior nas amostras que foram confeccionadas sem vibração e absorção de água (Figs. 5 e 6) e sinterizadas por queima única.

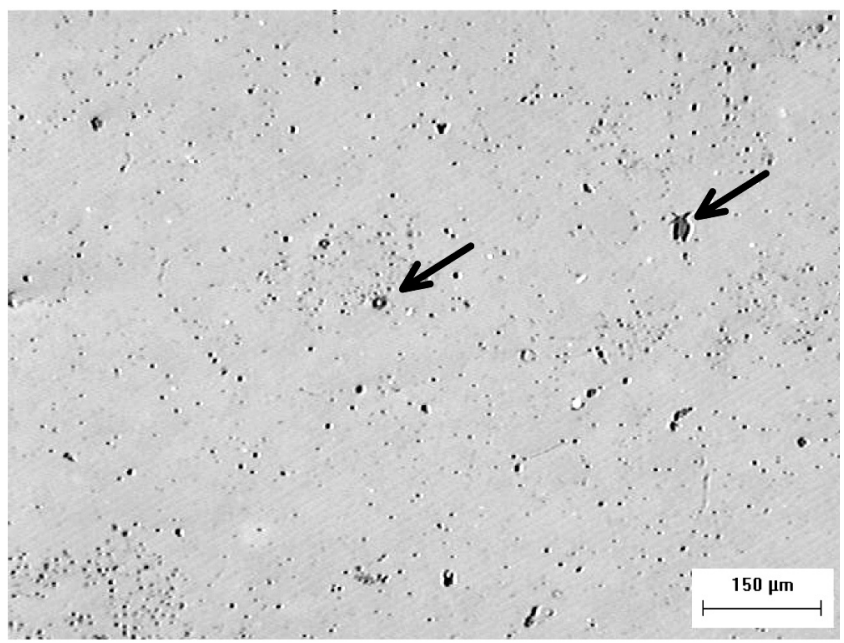

Figura 5: Microscopia ótica da cerâmica dentária A1.

[Figure 5: Optical micrograph of the A1 dental ceramic.]

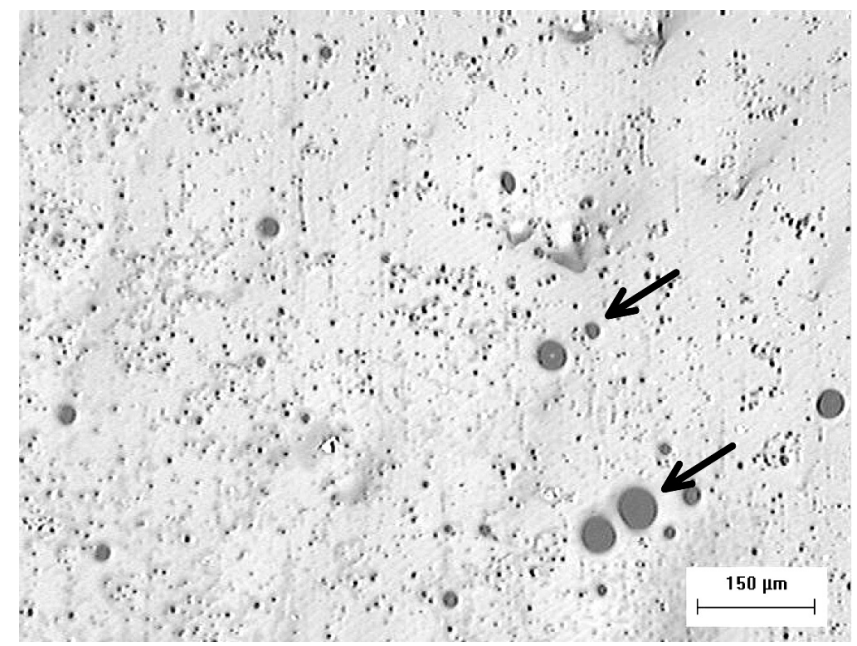

Figura 6: Micrografia óptica da cerâmica dentária B1.

[Figure 6: Optical micrograph of B1 dental ceramic.]

O maior teor de água associado a uma técnica de condensação sem vibração promove uma aleatoriedade na posição das partículas e maior afastamento entre as partículas formando-se espaços vazios em determinadas áreas. Com 
isso, o coalescimento das partículas durante a sinterização é dificultado e formam-se poros na microestrutura.

As amostras que foram condensadas sob vibração e absorção de água apresentaram um menor número de poros (Figs. 7 e 8).

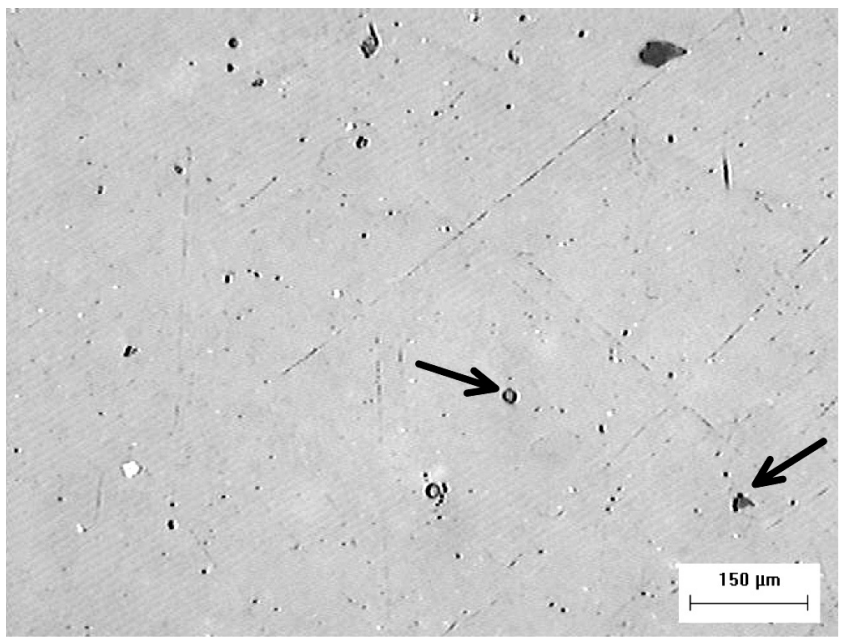

Figura 7: Micrografia óptica da cerâmica dentária A2.

[Figure 7: Optical micrograph of the A2 dental ceramic.]

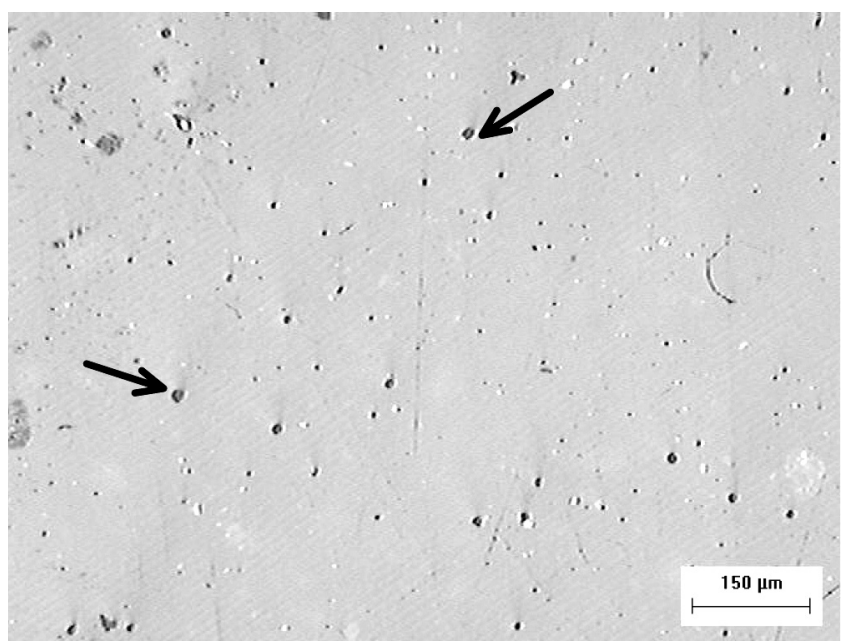

Figura 8: Micrografia óptica da cerâmica dentária B2.

[Figure 8: Optical micrograph of the B2 dental ceramic.]

A condensação sob vibração e absorção de água com papel absorvente elimina a quantidade de água em excesso aproximando as partículas do pó. A vibração permite um melhor empacotamento do material com distribuição trimodal, pois partículas menores se posicionarão entre os espaços deixados por partículas médias e grandes. Além do mais, o excesso de água é eliminado para a superfície. Sendo assim, as partículas coalescerão facilmente, durante a sinterização, diminuindo o número de vazios e consequentemente de poros na microestrutura.

Segundo alguns autores, a condensação realizada pelo técnico em prótese dentária poderia promover variações na distribuição das partículas devido ao método de absorção da água por capilaridade que deslocaria partículas grandes do centro da massa em direção à superfície [19].

A queima para a cerâmica odontológica ocorre sob vácuo de aproximadamente um décimo da pressão atmosférica para reduzir a porosidade do material. Em uma temperatura de, por volta, $55^{\circ} \mathrm{C}$ abaixo da temperatura de queima, o vácuo é liberado e a pressão no interior do forno aumenta cerca de 10 vezes, de $0,1 \mathrm{a} 1 \mathrm{~atm}$. Os poros são então comprimidos e o volume total de porosidade é reduzido. Nem todos os poros são eliminados, o que irá depender também da técnica de compactação antes da queima [1].

As cerâmicas condensadas sem vibração e absorção de água, submetidas a quatro queimas, apresentaram um menor número de poros. Entretanto, as queimas repetidas promoveram o aparecimento de trincas na microestrutura cerâmica (Figs. 9 e 10).

A Fig. 11 revela a extensão de trincas na cerâmica A após

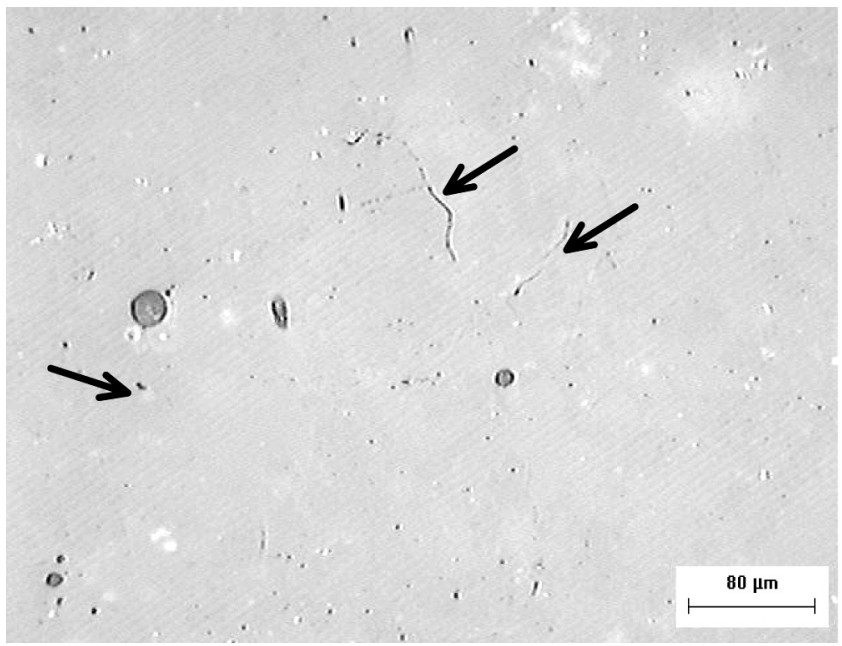

Figura 9: Presença de trincas na microestrutura da cerâmica dentária A3.

[Figure 9: Cracks in the microstructure of the A3 dental ceramic.]

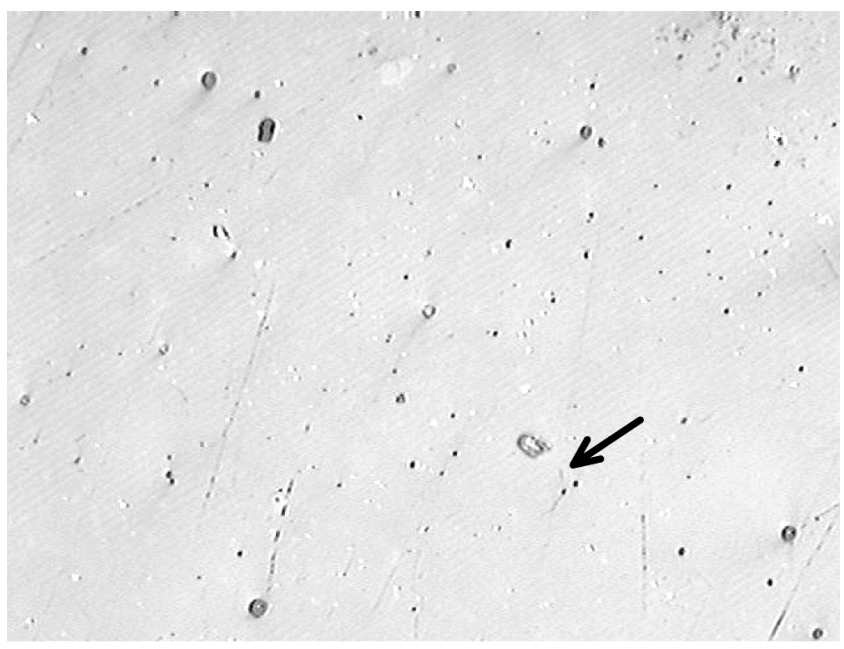

Figura 10: Presença de trinca superfície da cerâmica dentária B3. [Figure 10: Crack in the microstructure of the B3 dental ceramic.] 


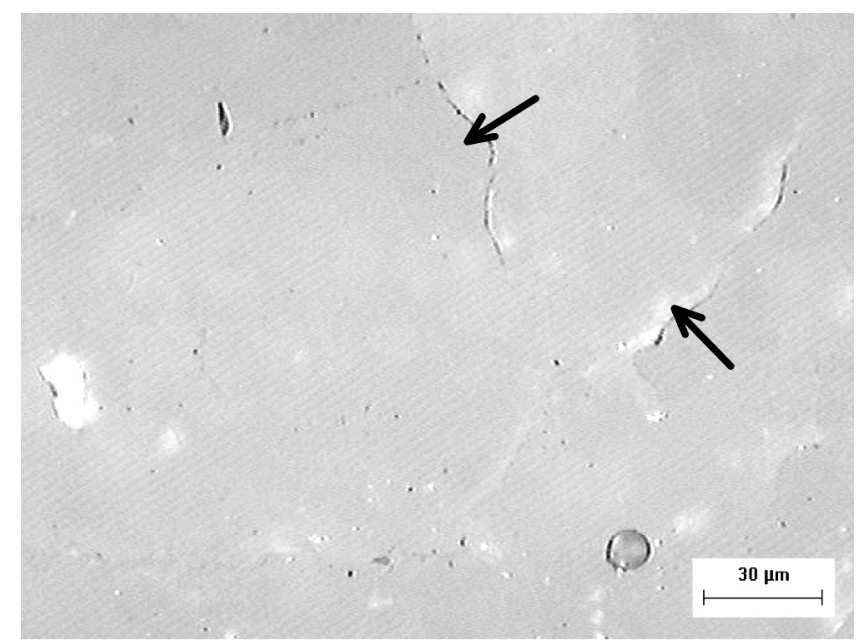

Figura 11: Extensão de trincas na microestrutura da cerâmica dentária A3.

[Figure 11: Crack in the microstructure of the A3 dental ceramic.]

sinterização em quatro queimas, condensada sob vibração com absorção de água.

$\mathrm{Na}$ Fig. 12 a micrografia obtida por microscopia eletrônica de varredura revela trincas próximas aos grãos das fases 1 e 2 .

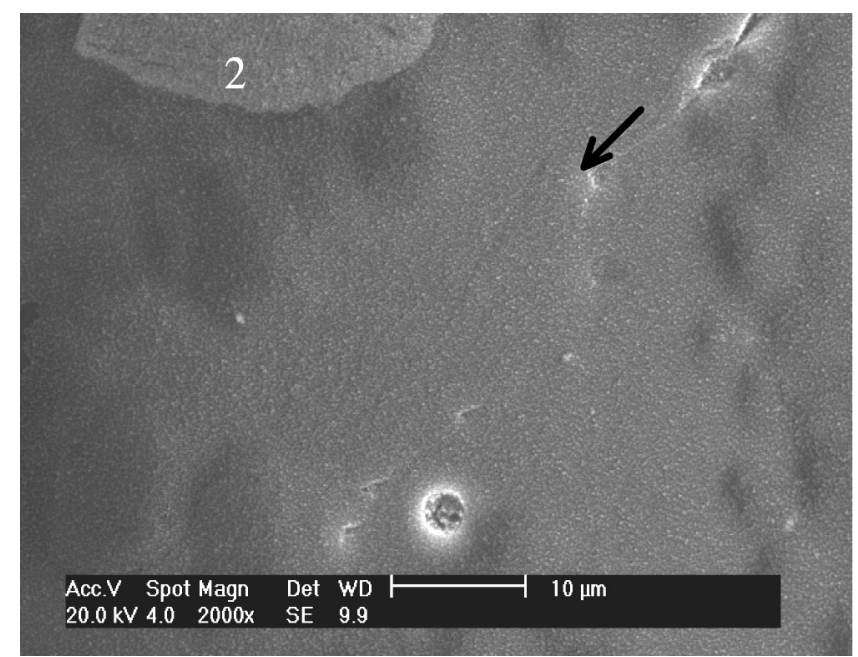

Figura 12: Micrografia obtida por MEV da cerâmica dentária A3. Presença de trinca entre a fase de leucita (seta 1) e uma fase corante (seta 2).

[Figure 12: SEM micrograph of A3 dental ceramic. Crack between leucite and coloring phase.]

A análise química pontual por EDS da fase 1 revela teores de $\mathrm{Si}, \mathrm{Al}, \mathrm{K}$ e $\mathrm{O}$, confirmando a hipótese de que esta fase consiste de leucita, após associação com os resultados obtidos por DRX. Conforme alguns estudos [2, 20] a leucita apresenta um tamanho médio de $5 \mu \mathrm{m}$ e possui uma geometria arredondada, concordando com o aspecto da fase analisada. Já a análise química da fase 2 indica um alto teor de $\mathrm{Al}$ e um certo teor de $\mathrm{Zn}$. Há a hipótese de que a fase 2 pode ter sido adicionada para proporcionar uma cor desejada para o material. As fases opacificantes formadas por óxidos de $\mathrm{Zr}$ e Sn não estão nesta cerâmica. Portanto, as únicas fases presentes tornam esta cerâmica mais translúcida para simular camadas de estruturas dentináriass perdidas.

Segundo alguns estudos, o coeficiente de expansão térmica da leucita varia de $22,3 \times 10^{-6 /} /{ }^{\circ} \mathrm{C}$ a $25 \times 10^{-6} /{ }^{\circ} \mathrm{C}\left(400{ }^{\circ} \mathrm{C}\right)$, para a leucita tetragonal, e $21,5^{\circ} \mathrm{Cx} 10^{-6} /{ }^{\circ} \mathrm{C}\left(400-700^{\circ} \mathrm{C}\right)$ para a leucita cúbica. Assim, $15-25 \%$ do teor de leucita é o suficiente para aumentar o coeficiente de expansão térmica da matriz vítrea de $10,7 \times 10^{-6 /} /{ }^{\circ} \mathrm{C}$ para $13-15 \times 10^{-6 /} /{ }^{\circ} \mathrm{C}$ necessária à união da porcelana com ligas metálicas $[6,8]$. A leucita apresenta adicionalmente uma transformação polimórfica de estrutura tetragonal para cúbica acompanhada na temperatura de $625^{\circ} \mathrm{C}$ por uma grande mudança de volume $[6,8]$. A leucita é uma fase cristalina com alto coeficiente de expansão térmica cujo volume de fração na matriz vítrea pode marcadamente afetar o coeficiente de expansão térmica do material cerâmico, já que o coeficiente de expansão térmica dos feldspatos encontram-se em torno de 9$10 \times 10^{-6 /} \mathrm{C}[1]$.

As trincas entre as fases cristalinas sugerem que a diferença de coeficientes de expansão térmica entre as fases cristalinas e a fase de matriz vítrea, durante o resfriamento do processo de sinterização, gera tensões residuais. Após queimas repetidas, as tensões podem ultrapassar a tensão máxima de tração que a fase vítrea pode suportar até sua fratura. As queimas repetidas podem sinterizar melhor o material diminuindo o número de vazios. No entanto, o aparecimento de trincas é iminente e indesejável para a aplicação do material. Uma vez presentes, as trincas se propagam catastroficamente, sendo locais de concentrações de tensões durante o processo mastigatório, tornando o material menos resistente mecanicamente. Além disso, substâncias ácidas oriundas do biofilme bacteriano e da dieta alimentar podem se concentrar nas trincas potencializando o seu crescimento devido à degradação do material cerâmico.

A micrografia da amostra de cerâmica prensável revela que a técnica de termopressão não diminui consideravelmente o número de poros (Fig. 13).

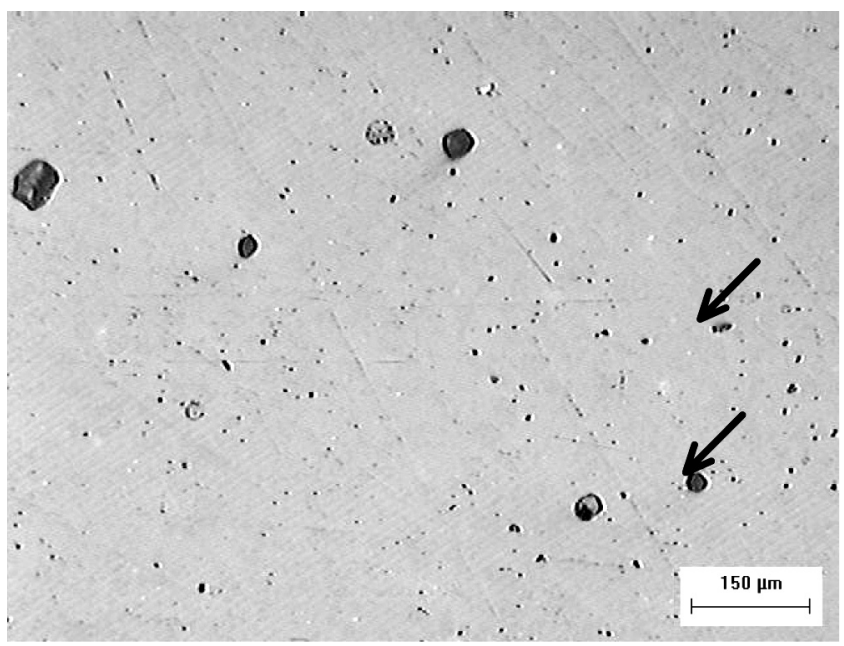

Figura 13: Micrografia óptica da cerâmica dentária termoprensável C. [Figure 13: Optical micrograph of the hot-pressed dental ceramic.] 
Apesar da técnica de sinterização em termopressão ser bem controlada, o número de poros continua sendo alto para uma cerâmica que não sofre influência manual em sua sinterização. A técnica manual de condensação e posterior tratamento térmico em forno, para as cerâmicas convencionais, proporciona uma quantidade de poros semelhantes à cerâmica termoprensável indicando que a técnica manual adequada de condensação sob vibração e absorção com papel absorvente pode diminuir o número de poros satisfatoriamente. Entretanto, a quantidade de água não é controlada e muitos técnicos não utilizam a técnica de vibração ultrasônica que poderia minimizar a presença de poros na microestrutura.

\section{CONCLUSÕES}

O número de poros foi maior nas cerâmicas condensadas com a ausência de vibração e sem absorção da água.

A condensação sob vibração e absorção da água aplicada em materiais com distribuição de partículas trimodal pode diminuir consideravelmente o número de vazios durante a sinterização.

As queimas repetidas, apesar de favorecerem à redução do número de poros, podem promover o aparecimento de trincas.

A cerâmica termoprensável estudada apresenta uma quantidade de poros semelhante ao das cerâmicas convencionais condensadas e sinterizadas adequadamente.

\section{AGRADECIMENTOS}

Aos laboratórios de Cimentos, Microscopia ótica e Materiais Cerâmicos da UFRN pela disponibilidade na preparação das amostras e ensaios microestruturais. Ao laboratório de prótese dentária Dental Nunes pelo apoio na confecção das amostras.

\section{REFERÊNCIAS}

[1] K. J Anusavice, Phillips: Materiais Dentários, 11ª Ed. (2005) 764p.

[2] A. Tsetsekou, T. Papadopoulos, O. Abamopoulos, Microstructure effect on the properties of a commercial lowfusing dental porcelain, J. Mater. Sci: Mater. Med. 13 (2002) 407-416.

[3] K. C. Cheung, B. W. Darvell, Sintering of dental porcelain: effect of time and temperature on appearance and porosity, Dent. Mater. 18 (2002) 163-173.

[4] W. M. Palin, G. J. P. Fleming, P. M. Marquis, An evaluation of the techinique sensitivity of a hydrothermal low-fusing dental ceramic, J. Dent. 29 (2001) 443-449.
[5] P. F.Cesar, H. N. Yoshimura, W. G. Miranda Jr., C. Y. Okada, Correlation between fracture toughness and leucite content in dental porcelains, J. Dent. 33 (2005) 721-729.

[6] J. L. Ong, D. W. Farley, Quantification of leucite concentration using X-ray diffraction, Dent. Mater. 16 (2000) 20-25.

[7] P. W. Piché, W. J. O’Brien, C. L. Groh, K. M. Boenke, Leucite content of selected dental porcelains, J. Biom. Mater. Res. 28 (1994) 603-609.

[8] J. R. Mackert Jr., S. W. Twiggs, AL Evans-Williams, Isothermal anneal effect on leucite content in dental porcelain. J. Dent. Res. 74 (1995) 1259-1265.

[9] G. Isgró, C. J. Kleverlaan, W. Hang, A. J. Feilzer, Thermal dimensional behavior of dental ceramics, Biomaterials 25, 12 (2004) 2447-2453.

[10] G. Isgró, C. J. Kleverlaan, W. Hang, A. J. Feilzer, The influence of multiple firing on thermal contraction of ceramic materials used for the fabrication of layered all-ceramic dental restorations, Dent. Mater. 21 (2005) 557-564.

[11] J. C. M. Souza, Avaliação de sistemas metalocerâmicos dentários metalizados mecanicamente com titânio, Diss. Mestrado, UFRN (2006) 89p.

[12] M. Hermann, R. Rottenegger, J. Tinschert, R. Marx, The effect of corrosive environment on the porcelain-to-metal bond - A fracture mechanics investigation, Dent Mater. 8 (1992) 2-6.

[13] Y. M. Alkhiary, S. M. Morgano, R. A. Giordano, Effects of acid hydrolisis and a mechanical polishing on surface residual stresses of low-fusing dental ceramics, J. Prost. Dent. 90, 2 (2003).

[14] J. A. Griggs, A. Kishen, K. N. Le, Mechanism of strength increase for a hydrothermal porcelain, Dent. Mater. 19 (2003) 625-631.

[15] S. W. Twiggs, J. R. Mackert Jr., A. L. Oxford, J. W. Ergle, P. E. Lockwood, Isothermal phase transformations of a dental porcelain, Dent. Mater. 21 (2005) 580-585.

[16] J. R. Mackert Jr., A. L. Evans, Quantitative X-ray diffraction determination of leucite thermal instability in dental porcelain, J. Am. Ceram. Soc. 74 (1991) 450-453.

[17] A. E. R. Westman, H. R. Hugil, The packing of particles, J. Am. Ceram. Soc. 13 (1930) 767-779.

[18] R. K. MacGeary, Mechanical packing of spherical particles, J. Am. Ceram. Soc. 44 (1961) 513-522.

[19] S. T. Rasmussen, W. Ngaji-Okumu, K. Boenke, W. J. O'Brien, Optimum particle size distribution for reduced sintering shrinkage of a dental porcelain, Dent. Mater. 13 (1997) 43-50.

[20] M. Guazzato, A. Albakry, S. P. Ringer, Strength, fracture toughness and microstructure of a selection of all-ceramic materials. Part I e II, Dent. Mater. 20 (2004) 441-456.

(Rec. 05/03/2007, Ac. 04/05/2007) 